\title{
Analysis of Taiwan's English Curriculum and Teaching Materials from the Perspective of English as a Lingua Franca
}

Shu-wen Lin ( $\sim$ a7210279@gmail.com )

Original article

Keywords: English as a lingua franca, Curriculum, Teaching material

Posted Date: July 15th, 2020

DOI: https://doi.org/10.21203/rs.3.rs-42325/v1

License: (c) (i) This work is licensed under a Creative Commons Attribution 4.0 International License.

Read Full License 


\section{Abstract}

This content analysis study explores the extent to which Taiwanese senior high school English curriculum and teaching materials reflect an English as a lingua franca (ELF) perspective. The background for this study is changes to Taiwanese education policy, the development of research into teaching ELF, and the vital role of curriculum and teaching materials in English language learning. Data collected for analysis include Taiwan's 12-year curriculum guidelines for English education and the teaching materials written in line with the curriculum. These data were examined and discussed within an adapted Global Englishes Language Teaching framework, focusing on representations of targets and norms, goals and criteria, and orientation and ownership. This study shows that, despite the curricular rhetoric of recognition for variations of English, Taiwanese senior high school students are not sufficiently prepared for real-life intercultural communication or to take ownership of English. Alternatives supported by this study include (1) presenting students with diverse users and cultures of English, sources of input, and communication strategies, and (2) engaging students in experimenting with and reflecting on their language use and cultural encounters.

\section{Background}

Drawing on both the literature and the researcher's experience, this study analyzes Taiwan's English language education from the perspective of English as a lingua franca (ELF). An investigation of her professional identity as a teacher led the researcher to pursue English as a means of communication for intercultural interaction. At the inception of her English language teaching (ELT) career overseas, the researcher, a Taiwanese English teacher in Japan, felt a sense of self-marginalization as neither a native English-speaking teacher nor a local, nonnative-English-speaking teacher. As she considered how to take professional responsibility and accountability instead of positioning herself within potential victimhood of being an outsider in her current community, she became aware of the concept of ELF. She became convinced that any interlocutor's linguistic, cultural, and life experiences are resources for learning and teaching English (Rivers, 2018). This realization resonates with Holliday's (2013) notion of "cultural belief" (Holliday, 2013, p. 21), which challenges the native English speakers' sole ownership of English and the superiority of stereotypical English native-speaking norms. English language education, alternatively, should uphold the plurality and multiplicity of English and transform linguistic and cultural ideology (Chern, 2014).

Currently, English is used across regional and linguistic boundaries, functions as a lingua franca, and is considered "a contact language between speakers or speaker groups when at least one of them uses it as a second language" (Mauranen, 2017, p. 8). The present study is based on the growing trend internationally of using English in the globalized world, described as "linguistically, culturally, and functionally diverse" by Matsuda in an interview with Yeo (2018, p. 121). Since the beginning of the 21st century, curricular and pedagogical practices that reflect the fluid and dynamic use of English by various speakers have been proposed (e.g., Jenkins, 2002; McKay, 2002). Over the past decade, studies have explored the pedagogical implications of English as a language of international communication (e.g., 
Sifakis, 2009), cultural aspects of ELF (e.g., Baker, 2009, 2011), and the implications of ELF research for teaching materials (e.g., Bayyurt \& Altinmakas, 2012), language testing (e.g., Jenkins, 2006), and teacher education (e.g., Sifakis, 2007). ELF-related research on English pedagogy, curricula, and teaching materials are gaining more and more attention in different parts of the world, across education levels. In Taiwan, although ELF research has drawn interest, it is still at an initial developing stage (Suzuki et al., 2017) and has focused on higher education (e.g., Curran \& Chern, 2017; Luo, 2017, 2018; Tai, 2019). The researcher agrees with Lee (2012) that developing a "more comprehensive and accurate understanding of English sociolinguistics" (Lee, 2012, p. 155) is equally essential for younger high school students. The researcher also believes that this is a suitable time to conduct this proposed study because Taiwan's English language education has been drastically transformed because of the implementation of the latest 12-year curriculum guidelines.

In response to the demand for internationalization and global mobility, Taiwan, a traditional Expanding Circle country (Kachru, 1992), has been striving to improve English learning and teaching. The Taiwanese Ministry of Education (MOE) announced the latest 12-year Basic Education Curriculum Guidelines in 2014 and implemented the curriculum at the beginning of the school year in autumn 2019. The objectives of Taiwan's English curriculum comprise a life-long learning attitude and capability; thinking skills; intercultural competence; and communication skills in listening, speaking, reading, and writing. Additionally, the current curriculum shows an intention to empower learners with ownership of English, increase awareness regarding variations of English for international communication, and enhance practical communication skills (Chern, 2014; Taiwanese Ministry of Education, 2018; Yeh, 2019). In addition to the term ELF, several related concepts such as global Englishes and English as an international language focus on "the plurality of English and legitimacy of such variation" (Rose \& Galloway, 2019, p. 11) and address issues of "what English is, who owns it and how it should be used" (Rose \& Galloway, 2019, p. 11). An ELF perspective problematizes the traditional model of ELT and argues for alternative approaches to learning and teaching the English language and culture (Baker, 2015; Galloway, 2017).

In the Taiwanese school system, the curriculum guidelines provide national direction in terms of objectives, content, and management of content. The top-down imposition of the curriculum guidelines may be interpreted and implemented through different approaches by various agents, including textbook publishers. Glasgow and Paller (2016) identified textbooks as "a manifestation of policy representation, or a tangible product of the intended policies" (Glasgow \& Paller, 2016, p. 170). However, they found a gap between policy intention and textbook representation. In addition, despite the role of textbooks as a key source of input and the main medium between teachers and students, a mismatch remains between the representations of language and culture in ELT materials and the actual contexts and uses of English in today's globalized world (Baker, 2015; Galloway, 2017; McConachy \& Hata, 2013; Vettorel \& Lopriore, 2013). These arguments are the rationale for selecting the analysis objects in the present study.

With regard to the diversity and heterogeneity of English and a movement away from "native" speaker norms, Galloway and Rose provided an umbrella framework to "unite the calls for change in ELT" 
(Galloway \& Rose, 2015, p. 4). They later updated the Global Englishes Language Teaching (GELT) framework in 2018 and argued that it could be integrated and applied to the ELT curriculum and materials analysis (Galloway \& Rose, 2018). The degree of "ELFness", according to this framework, can be examined along continua of target interlocutors, owners, target cultures, teachers, norms, role models, sources of material, and first languages and own cultures. Instead of seeing English as a "foreign" language used to communicate chiefly with "native" speakers, the GELT framework proposes that all users of English are the target interlocutors and owners of the language. As such, the ideal teachers and role models are not necessarily native English speakers (NES), but rather strategic, expert users of English. These users, their communities, and contexts constitute an authentic source of materials. In addition, culture and linguistic norms are not static and ought to be critically discussed. The language users draw on their multilingual and multicultural resources to communicate successfully, and accordingly, their first language and own culture are seen as a resource instead of a hindrance or interference (Galloway, 2017; Galloway \& Rose, 2015, 2018; Rose \& Galloway, 2019). The next two sections describe how this framework was used to interpret the data and present the analysis results.

\section{Methodology}

The researcher analyzed Taiwan's current curriculum guidelines and the teaching material (with the highest market share) written according to the curriculum in order to

1. analyze the extent to which Taiwan's current curriculum guidelines reflect the role of ELF and

2. evaluate the extent to which Taiwanese senior high school English teaching materials reflect the role of ELF.

The analysis was informed by an adapted GELT framework (Galloway \& Rose, 2018) introduced in the previous section, focusing on representations of targets and norms, goals and criteria, and orientation and ownership.

Taiwan's 12-year Basic Education Curriculum was implemented in September 2019. This curriculum is competency-driven, emphasizing "students' ability in applying their knowledge to real-life scenarios" (Taiwanese Ministry of Education, 2018). The unit of analysis for the curriculum guidelines was individual learning performances the curriculum was designed to induce. These learning performances reveal the abilities or strategies students are expected to develop in senior high school, and they consist a total of 95 units of analysis.

The latest materials written in line with the 12-year Basic Education Curriculum Guidelines were first published in 2019, and students started using the materials in the first semester in September. The material selected for analysis has the highest market share (68\%) in Taiwan. The complete material package includes a student book, workbook, teacher's manual, audiovisual aids, and other supplementary resources. This research focused on the student book, teacher's manual, and audiovisual media. The basic unit of analysis was each section of the textbook units, including warm-up, reading strategy, 
intensive reading selection, graphic organizer, comprehension exercises, vocabulary and phrases, sentence patterns, and listening sections.

\section{Results And Discussion}

\section{Taiwanese Senior High School English curriculum}

Among the 95 specified learning performances, that which addresses students' ability to "understand what speakers with different accents or linguistic backgrounds are saying" has been argued to reflect the expanding contexts and uses of English (Taiwanese National Academy for Educational Research, 2018; Yeh, 2019). This learning performance is also asterisked, which means that it is considered to be of a higher level. Students' adopting this learning performance is not mandatory, and pedagogical tasks for achieving this learning performance should be adjusted to meet students' individual instructional needs.

The researcher argues that although this part of the curriculum is relevant to the global status of English in its focus on diversity in language use, it does not adequately represent ELF research. Galloway (2017) and Selvi (2019), among other scholars, have strongly recommended reconceptualization of ELT, including linguistic norms, standards, ownership, ideology, and cultural identity, for pedagogical decisions to be aligned with the current realities of English. With reference to the GELT framework (Galloway \& Rose, 2018), the researcher posits that two other learning performances are pertinent to the nature of ELF, namely the ability to

- use linguistic and nonlinguistic communicative strategies (such as asking for repetition, euphemism, talking around words, gestures, and facial expressions) and

- integrate cultural knowledge and linguistic competence in solving real-life problems.

These learning performances emphasize the strategic use of English and learners' multilingual and multicultural resources in communication. The above mentioned learning performances should not be considered as "optional" parts of the curriculum as Yeh (2019) suggested because the curriculum aims to prepare students for real-life communicative situations where the use of English is essentially "linguistically, culturally, and functionally diverse" (Yeo, 2018, p. 121).

\section{ELT materials}

The student book and teacher's manual are coauthored by Taiwanese and NES ELT professionals. The student book is written mainly in English, except for the sentence pattern section of each lesson, whereas the teacher's manual is bilingual (English and Chinese). The material is subdivided into nine units, with one review unit after every three units. Each unit has a standardized warm-up, reading strategy, intensive reading selection, graphic organizer, comprehension exercises, vocabulary and phrases, sentence patterns, and listening section. Despite the claim that the material aims to develop students' competence in oral expression and communication capability, a substantial proportion of the content is dedicated to literacy-based learning. Audiovisual aids are provided for the warm-up, intensive reading selection, 
vocabulary and phrases, and listening sections. The following subsections present and discuss the results of the analysis within the GELT framework.

\section{Targets and norms}

The ELFness of the material was examined based on how English users and English uses are represented along the continua of NES as target interlocutors-all English users as target interlocutors; fixed native English cultures as target cultures-fluid cultures as target cultures; standard English as norms-diverse, flexible, and multiple forms as norms; and first language and own culture as hindrance and source of interference-first language and own culture as a resource (Galloway \& Rose, 2018; Ke, 2012; Takahashi, 2011).

Of the 12 unit topics, 4 are nation specific-the contents of these units refer to or are associated with the culture or history of a specific country (Takahashi, 2011). Of them, two involve multicultural themes-their topics involve more than one country (Takahashi, 2011)-concerning Expanding Circle countries, including France, Thailand, Spain, Portugal, and Sweden. The other two involve monocultural topics; one introduces the history and meaning of the Statue of Liberty in the United States, and the other discusses a prominent Taiwanese documentary director. However, the multicultural- and Taiwan-themed topics are dealt with in the review units, which are likely to be taken lightly by teachers. In addition, the intensive reading selection in each unit is hardly in dialogic form. Moreover, seven of nine listening sections comprise monologic recordings, and it cannot be determined whether the dialogs in the other two sections are between speakers from the same country or different countries.

The implications of ELF in the teaching material were found in the expanding cultural bases and the use of students' first language to facilitate their English learning. First, consistent with the research results of $\mathrm{Ke}$ (2012) on the trend of contemporary ELT materials, more units (two-thirds) discuss issues in a universal manner. This "can help prepare students to engage in future conversations on global issues while also helping them see how the same issues may be understood by English users from different cultural contexts" (Matsuda \& Matsuda, 2017, p. 70). Furthermore, a Chinese description or explanation in syntactic and pragmatic terms is provided with the sentence pattern section of each unit in the material in support of student learning. This indicates that students' first language is seen as a resource instead of a hindrance or interference (Galloway, 2017).

However, alternatives in the teaching material are necessary for capturing the concept of ELF, as accurate representation of authentic English usage in real contexts is lacking. The material still depends on the "native English" norms and contains solely static or factual cultural information. First, consistent with the finding of Ke (2012), English usage in this material is rarely depicted as between two or more nonnative English speakers, despite educational reforms in the past decade. In line with the contention of Rose and Galloway (2019), even though it is claimed that the material portrays authentic language usage with support from corpus-based and multimedia resources, it primarily draws from media of Anglophone countries, particularly the United States. 
Additionally, most audiovisual aids accompanying the package exhibit phonological features of native English speech, especially the American variety, except for the audio content of one review unit. In this unit, Taiwanese and Singaporean accents are used in addition to the American accent, which is explicitly indicated in the teacher's manual. Although the material represents an attempt to create exposure to multiple varieties in the classroom (Galloway, 2017; Selvi, 2019), the representations of language and culture are overly generalized and simplistic (Baker, 2015; McConachy \& Hata, 2013). Furthermore, the conformity to native English "conventions" (Yeh, 2019) may mislead students to view their creative and flexible but nonstandard use of language resources as "errors" or "signs of incompetence" (Galloway, 2017, p. 476). Students are likely to associate stereotypes with particular nations or groups of people. Scholars (e.g., Baker, 2015; Hino \& Oda, 2015; McConachy \& Hata, 2013) have recommended the integration of critical thinking activities into classrooms and teaching materials. Unfortunately, multicultural-themed topics are dealt with in the review units and not accompanied by postreading discussion-based activities, as with the other units; this limits students' opportunities to approach the issues from varied, alternative viewpoints.

\section{Goals and criteria}

From an ELF perspective, the goal of ELT is toward successful communication. In Taiwan, nonetheless, a main goal of studying English has traditionally been passing entrance examinations to gain access to higher education. Accordingly, the pedagogical tasks in teaching materials are often geared to exam preparation (Chou, 2017; Ke, 2019; Tseng, 2019; Yu, 2019). The findings of this study agree with those of $\mathrm{Yu}$ (2019), showing that the literacy is more prominent in the material (three-quarters of the sections in each unit) and that more emphasis is placed on strategy instruction for reading and writing abilities than for listening and speaking. Concerning communication capability, contrary to policy rhetoric, listening instruction is "comprehension-based and testlike" (Chou, 2017, p. 10), and speaking output involves no interaction or weak interactions between students and their peers or teacher. The use of English is limited to classroom settings.

Instead of communication, the approach to literacy skills in the material is preparing students for entrance examinations, which positions English as a foreign language (Ke, 2019; Yu, 2019). In consonance with the publisher's emphasis on the contribution of native English writers, of the 12 intensive reading selections, 8 are original works of native English writers, 2 are adopted from the original works of American authors, 1 is coauthored by Taiwanese and NES ELT professionals, and only 1 is independently written by a Taiwanese writer. Thus, Anglophone discourses remain dominant in the material, which is in contrast with the ELF proposals for bringing literary works from multiple cultural contexts and critical literacy into the classroom (Baker, 2015; Selvi, 2019). Moreover, although not explicitly specified, students' written output is likely to be aimed at an audience of college entrance examiners (Tseng, 2019) instead of an international audience (Verzella \& Tommaso, 2014). Demonstration of proficiency in the lexicon, collocation, morphosyntax, text structure, and genre production (relevant to the vocabulary and phrases, sentence patterns, and graphic organizer sections) receives more weight than do practice targeting comprehensibility and communicative effectiveness 
(Verzella \& Tommaso, 2014; Yeh, 2016, 2019). No pedagogical tasks suggested in the teacher's manual reach beyond in-class, student-to-student, or student-to-teacher communication. This ignores the diverse contexts and forms of communication outside the classroom that the students have participated in, such as virtual networks and physical mobility, and their benefits related to learning and teaching English (Lopriore, 2017).

The apparent lack of pedagogical tasks for communication capability development is a fundamental weakness of the material. No textbook unit section focuses on speaking practice. Furthermore, none of the reading tasks and few of the listening tasks are constructed in dialogic form (previously described in the subsection entitled "Targets and norms"). Speaking abilities, despite the recognition of their value in the curriculum guidelines (see the first subsection in "Results and discussion"), are given minor consideration because they are not tested in entrance examinations (Chou, 2017; Yu, 2019). To cultivate the learning performance of "using linguistic and nonlinguistic communicative strategies" and "solving real-life problems" stated in the curriculum guidelines, ELF research must be referred to. Naturally, an individual will encounter problems when communicating with interlocutors from various linguacultural backgrounds and must employ devices and strategies to cope with them. Researchers (e.g., Lopriore, 2017; Lopriore \& Vettorel, 2015) have called for teaching materials that (1) expose students to and raise their awareness of the plurality and multiplicity of English today, (2) encourage students to experiment and reflect on their use of strategies for "making sense, negotiating meaning, co-constructing understanding" (Seidlhofer, 2011, p. 198), and (3) empower students to use English independently beyond the school context. Their achievement is judged not by whether they adhere to "standard norms or the convention of NS [native English speaker] usage" (Lopriore \& Vettorel, 2015, p. 26; words in square brackets added by the author) but based on whether they can "initiate, establish and maintain meaningful and effective communication" (Lopriore \& Vettorel, 2015, p. 26).

As the goal and criteria of the pedagogical tasks contained in the teaching material orient more toward "linguistic competence" than "communicative capability" (Hemmi, Mackenzie, \& Yokomoto, 2019, p. 10), the tasks provide students with limited opportunities to learn how to use their linguistic and nonlinguistic resources. The goal for English competence development of fostering students' ability to effectively communicate in real-life scenarios cannot adequately be implemented through this material.

\section{Orientation and ownership}

Although the curriculum guidelines advocate the global character of the English language, extending ownership of the English language and acknowledging the legitimacy of variations of English (Taiwanese Ministry of Education, 2018), the teaching material does not introduce this concept and maintains an orientation toward native English norms. As explained in the previous discussion, the phonological, morphosyntactic, pragmatic, and discourse-based representations in this material mostly conform to native English conventions. Additionally, static, knowledge-based information and pedagogical tasks confined to the classroom do not sufficiently reflect real-life English contexts and usage. 
Seilhamer described Taiwanese students who view themselves as "legitimate arbiters" of the use of English as "exceptional cases" (Seilhamer, 2015, p. 24). The orientation of English as a foreign language that is controlled by NES constrains students' creative and flexible use of language resources. Students are likely to be "penalized" (for example losing marks on assessed work) for their "non-normative use of language" (Hemmi et al., 2019, p. 11). As a result, students are deprived of "the opportunity to achieve user status" (Seilhamer, 2015, p. 22) and engage in a life-long learning pursuit of an ideal. A perception of inferiority to NES is also "learned" because of this power relationship (Huang, 2018; Ke, 2010). By contrast, an ELF perspective suggests that students should develop a realistic expectation of how, with whom, and in what context English is used. Through engagement in the processes of exposure, awareness-raising, experience, and reflection, as mentioned in the subsection "Goals and criteria", students are empowered to broaden their conception beyond the prescriptive, conventional, and stereotypical approach toward English language and culture. The greater the possibility students have to communicate with various interlocutors in diverse contexts, the further their language and cultural resources will extend, and vice versa (Hemmi et al., 2019). Thus, students are more likely to establish an authentic and autonomous identity as a legitimate owner of English by "accepting responsibility for English and taking control of how it uses and develops by users of diverse linguistic and cultural backgrounds" (Akkakoson, 2019, p. 241).

Before concluding this paper, the researcher would like to highlight the strengths and limitations of the current study. This study focused on a context that has often been neglected in related studies. The results revealed the extent to which the Taiwanese senior high school curriculum and the selected teaching material reflect the role of ELF; specifically, the results indicated how well the curriculum and teaching material prepare Taiwanese students to use the English that they are most likely to encounter outside the classroom. However, this study has potential limitations. The subjectivity inherent in researcher interpretation and the small data size are two concerns. Because this study was a preliminary investigation of the curriculum guidelines and senior high school English materials that were adopted less than 1 year ago, an extension on the research to collect long-term and comprehensive data to consider multiple researchers' interpretations is warranted.

\section{Conclusion}

The study found that the national curriculum guidelines have implications for educational practices in terms of how diversity in English language usage is conceptualized. However, apart from the explicit recognition of variation in accents and language use, the guidelines are insufficiently associated with communication, cultural capabilities, and language ownership. Written in keeping with the curriculum, the material selected for analysis encompasses topics that familiarize students with global issues and uses students' first language in facilitating English learning. However, with an English as a foreign language orientation, the material continues to present a stereotypical and normative representation of what English is, who owns it, and how it should be used, notwithstanding the growing global trend and curricular rhetoric. The researcher argues that the material does not adequately prepare students to participate in real-life communication scenarios and ultimately foster students' autonomy and ownership. 
ELF research is well positioned to provide an alternative to the normative approach of the material. According to the GELT framework, alternatives may be provided through the following approaches:

1. The variation in English may be illustrated in the material by, for instance, examples of diverse interlocutors, their effective communication strategies in various contexts, and the complex culture they belong to.

2. The pedagogical tasks in the material must facilitate students' experiment with and critical reflection on their language use and cultural encounters. The postreading discussion-based activities in this material are positive examples and should be expanding further.

3. The sources of input the material draws upon can be expanded well beyond Anglophone discourses to include those of English users in global contexts as well as local contributions.

The results of this study agree with those in the literature on the complexity of English learning and teaching (Baker, 2015). The present study also revealed that multiple stakeholders have a role in the interpretation and implementation of English education, including teachers, students, and examiners. The researcher's next project is to investigate teachers' pedagogical practices and underlying cognitions. In recognition of students' life experiences, such as their out-of-class activities and digitally mediated interactions with other people, research and pedagogical approaches may examine the reciprocal effects of life experiences, in-school English learning, and continuing development. Moreover, the interplay between the ELF perspective and school-based assessments and national examinations may provide another avenue for potential research.

Taiwan's English education is currently on the threshold of reconceptualization. An ELF orientation is a radical but realistic shift toward life-long, sustainable development of communication capability. In line with the fluid and dynamic nature of ELF, this study suggests the need for imagining alternative possibilities.

\section{Abbreviations}

ELF: English as a lingua franca; ELT: English language teaching; GELT: Global English language teaching; MOE: Ministry of Education; NES: Native English speakers

\section{Declarations}

\section{Ethics approval and consent to participate}

Not applicable.

\section{Consent for publication}

Not applicable.

\section{Availability of data and materials}


Not applicable.

\section{Competing interests}

The author declares that she has no competing interests.

\section{Funding}

Not applicable.

\section{Authors' contributions}

There is only one sole author.

\section{Acknowledgements}

The author would like to thank her colleague Gareth Humphreys for his constructive comments to help improve earlier versions of this paper. The author's sincere gratitude also goes Wallace Academic Editing for their assistance in editing the manuscript.

\section{References}

1. Akkakoson, S. (2019). Thai language learners' sense of English ownership. Journal of Language Teaching and Learning in Thailand, 58, 235-262.

2. Baker, W. (2009). The cultures of English as a lingua franca. TESOL Quarterly, 43(4), 567-592. doi:10.1002/j.1545-7249.2009.tb00187.x.

3. Baker, W. (2011). Intercultural awareness: Modelling an understanding of cultures in intercultural communication through English as a lingua franca. Language and Intercultural Communication, 11(3), 197-214. doi:10.1080/14708477.2011.577779.

4. Baker, W. (2015). Culture and complexity through English as a lingua franca: Rethinking competences and pedagogy in ELT. Journal of English as a Lingua Franca, 4(1), 9-30. doi:10.1515/jelf-2015-0005.

5. Bayyurt, Y., \& Altinmakas, D. (2012). A WE-based English communication skills course at a Turkish University. In A. Matsuda (Ed.), Principles and practices of teaching English as an International language (pp. 169-182). Bristol: Multilingual Matters.

6. Chern, C. (2014). The significance of English as a lingua franca for English teaching and learning

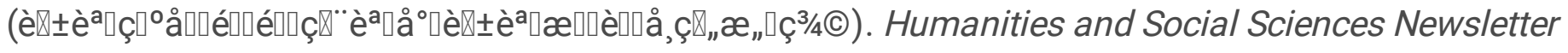
Quarterly, 16(1), 127-131.

7. Chou, M. H. (2017). Impacts of the Test of English Listening Comprehension (TELC) on teachers and teaching in Taiwan. Asian-Pacific Journal of Second and Foreign Language Education, 2(1), 191208. doi:10.1186/s40862-017-0028-9. 
8. Curran, J. E., \& Chern, C. L. (2017). Pre-service English teachers' attitudes towards English as a lingua franca. Teaching and Teacher Education, 66, 137-146. doi:10.1016/j.tate.2017.04.007.

9. Galloway, N. (2017). ELF and ELT teaching materials. In J. Jenkins, W. Baker \& M. Dewey (Eds.), Routledge handbook of English as a lingua franca (pp. 468-480). London: Routledge.

10. Galloway, N., \& Rose, H. (2015). Introducing global englishes. Abingdon: Routledge.

11. Galloway, N., \& Rose, H. (2018). Incorporating Global Englishes into the ELT classroom. ELT Journal, 72(1), 3-14. doi:10.1093/elt/ccx010.

12. Glasgow, G. P., \& Paller, D. L. (2016). English language education policy in Japan: At a crossroads. In R. Kirkpatrick (Ed.), English language education policy in Asia (pp. 153-180). Switzerland: Springer International Publishing.

13. Hemmi, C., Mackenzie, G., \& Yokomoto, K. (2019). An interview with Henry Widdowson. The Language Teacher, 43(6), 10-12. doi:10.37546/JALTTLT43.6-3.

14. Hino, N., \& Oda, S. (2015). Integrated practice in teaching English as an international language (IPTEIL): A classroom ELF pedagogy in Japan. In Y. Bayyuer \& S. Akcan (Eds.), Current perspectives on pedagogy for English as a lingua franca (pp. 35-50). Berlin: Walter de Gruyter GmbH \& Co KG.

15. Holliday, A. (2013). 'Native speaker' teachers and cultural belief. In S. A. Houghton \& D. J. Rivers (Eds.), Native-speakerism in Japan: Intergroup dynamics in foreign language education (pp. 17-28). Bristol: Multilingual Matters.

16. Huang, I. C. (2018). Power and ownership within the NS/NNS dichotomy. In B. Yazan \& N. Rudolph (Eds.), Criticality, teacher identity, and (in)equity in English language teaching (pp. 41-56). Cham: Springer International Publishing.

17. Jenkins, J. (2002). A sociolinguistically based, empirically researched pronunciation syllabus for English as an International Language. Applied Linguistics, 23(1), 83-103 + 156. doi:10.1093/applin/23.1.83.

18. Jenkins, J. (2006). The spread of EIL: A testing time for testers. ELT Journal, 60(1), 42-50. doi:10.1093/elt/cci080.

19. Kachru, B. B. (1992). The other tongue: English across cultures. Urbana: University of Illinois Press.

20. Ke, I. C. (2010). Global English and world culture: A study of Taiwanese university students' worldviews and conceptions of English. Journal of English as an International Language, 5(1), 81100.

21. Ke, I. C. (2012). From EFL to English as an international and scientific language: Analysing Taiwan's high-school English textbooks in the period 1952-2009. Language, Culture and Curriculum, 25(2), 173-187. doi:10.1080/07908318.2012.683530.

22. Ke, I. C. (2019). Has English been increasing tested as an international language? Evidence from 1956-2016. Language, Culture and Curriculum, 32(2), 191-206.

23. Lee, H. (2012). World Englishes in a high school English class: A case from Japan. In A. Matsuda (Ed.), Principles and practices of teaching English as an International Language (pp. 140-153). 
Bristol: Multilingual Matters.

24. Lopriore, L. (2017). Revisiting language teaching materials in a time of change. A Cor Das Letras, 18, 182-199. doi:10.13102/cl.v18iespecial.2668.

25. Lopriore, L., \& Vettorel, P. (2015). Promoting awareness of Englishes and ELF in the English language classroom. In H. Bowles \& A. Cogo (Eds.), International Perspectives on English as a Lingua Franca (pp. 13-34). London: Palgrave Macmillan.

26. Luo, W. H. (2017). A study of internationally-published English textbooks from the perspective of English as a Lingua Franca concerning content and pedagogy. Journal of Textbook Research, 10(2), 133-159. doi:10.6481/JTR.201708.

27. Luo, W. H. (2018). A study of Taiwanese University students' English use, learning goals and attitudes toward English as a lingua franca. Studies in Second Language Learning and Teaching, 8(4), 775-794. doi:10.14746/ssilt.2018.8.4.4.

28. Matsuda, A., \& Matsuda, P. K. (2017). Teaching English as an international language: A WE- informed paradigm for English language teaching. In E. L. Low \& A. Pakir (Eds.), World Englishes: Rethinking paradigms (pp. 64-77). London: Routledge.

29. Mauranen, A. (2017). Conceptualising ELF. In J. Jenkins, W. Baker \& M. Dewey (Eds.), Routledge handbook of English as a Lingua Franca (pp. 7-24). London: Routledge.

30. McConachy, T., \& Hata, K. (2013). Addressing textbook representations of pragmatics and culture. ELT Journal, 67(3), 294-301. doi:10.1093/elt/cct017.

31. McKay, S. L. (2002). Teaching English as an International Language: Rethinking goals and approaches. Oxford: Oxford University Press.

32. Rivers, D. J. (2018). Speakerhood as segregation: The construction and consequence of divisive discourse in TESOL. In B. Yazan \& N. Rudolph (Eds.), Criticality, teacher identity, and (in)equity in English Language teaching (pp. 179-197). Cham: Springer International Publishing.

33. Rose, H., \& Galloway, N. (2019). Global Englishes for language teaching. Cambridge: Cambridge University Press.

34. Seidlhofer, B. (2011). Understanding English as a lingua franca. Oxford: Oxford University Press.

35. Seilhamer, M. F. (2015). The ownership of English in Taiwan. World Englishes, 34(3), 370-388. doi:10.1111/weng. 12147.

36. Selvi, A. F. (2019). Incorporating global Englishes in K-12 classrooms. In L. C. De Oliveira (Ed.), The Handbook of TESOL in K-12 (Vol (2, pp. 83-99). West Sussex: John Wiley \& Sons.

37. Sifakis, N. (2007). The education of teachers of English as a lingua franca: A transformative perspective. International Journal of Applied Linguistics, 17(3), 355-375. doi:10.1111/j.14734192.2007.00174.x.

38. Sifakis, N. C. (2009). Challenges in teaching ELF in the periphery: The Greek context. ELT Journal, 63(3), 230-237. doi:10.1093/elt/ccn057. 
39. Suzuki, A., Liu, H., \& Yu, M. H. (2017). ELT and ELF in the East Asian contexts. In J. Jenkins, W. Baker \& M. Dewey (Eds.), Routledge Handbook of English as a lingua franca (pp. 494-505). London: Routledge.

40. Tai, H. Y. (2019). Investigation into tense-aspect patterns of Chinese ELF academic writing -A variationist's approach. English Teaching and Learning, 43(3), 277-295. doi:10.1007/s42321-01900029-y.

41. Taiwanese Ministry of Education. (2018). 12-year compulsory education English curriculum. Retrieved from https://cirn.moe.edu.tw/Upload/file/26192/74206.pdf.

42. Taiwanese National Academy for Educational Research. (2018). Handbook for subject English. Retrieved from https://www.naer.edu.tw/ezfiles/0/1000/img/67/122453112.pdf.

43. Takahashi, R. (2011). English as a Lingua Franca in a Japanese context: An analysis of ELF-oriented features in teaching materials and the attitudes of Japanese teachers and learners of English to ELForiented materials (PhD thesis). University of Edinburgh, Edinburgh.

44. Tseng, C. C. (2019). Senior high school teachers' beliefs about EFL writing instruction. Taiwan Journal of TESOL, 16(1), 1-39. doi:10.30397/TJTESOL.201904.

45. Verzella, M., \& Tommaso, L. (2014). Learning to write for an international audience through crosscultural collaboration and text-negotiation. Changing English: Studies in Culture and Education, 21(4), 310-321. doi:10.1080/1358684X.2014.968469.

46. Vettorel, P., \& Lopriore, L. (2013). Is there ELF in ELT coursebooks? Studies in Second Language Learning and Teaching, 3(4), 483-504. doi:10.14746/ssllt.2013.3.4.3.

47. Yeh, H. (2016). Prospects of English textbooks for elementary and high schools in view of draft curriculum guidelines for twelve-year basic education. Journal of Text, 9(3), 143-168. doi:10.6481/JTR.201612_9(3).05.

48. Yeh, H. (2019). Design and use of English textbooks for twelve-year basic education. Journal of Education Research, 303, 52-66. doi:10.3966/168063602019070303005.

49. Yeo, M. (2018). Preparing English language learners for the messy world of EIL: Interview with Aya Matsuda. RELC Journal, 49(1), 119-124. doi:10.1177/0033688217738822.

50. Yu, M. H. (2019). Literacy skills education from the perspective of English as a lingua franca: A case study on Taiwanese students' secondary English language education experience. In B. L. Reynolds \& M. F. Teng (Eds.), English literacy instruction for Chinese speakers (pp. 175-194). Singapore: Springer. 